\title{
Leptospires in field Rats in and around the laboratory animal facilities of Banglore, India
}

\author{
Vinodkumar, G., Rajeshwari, Y. B., Shivaraj ${ }^{1}$, U. Krishnamoorthy, Ansar Kamran² \\ Department of Livestock production and management, \\ Veterinary college, KVAFSU, Bangalore- 24. \\ 1. Institute of Animal Health and Veterinary Biologicals, Hebbal, Banglore, India. \\ 2. Department of Clinical Medicine, Veterinary college, KVAFSU, Bangalore- 24. \\ * Corresponding author email: vindy686@gmail.com
}

Received: 09-12-2010, Accepted:04-02-2011, Published Online: 16-07-2011

doi: $10.5455 /$ vetworld.2011.410-412

\begin{abstract}
The present study was undertaken to determine the prevalence of leptospires in field rats in and around laboratory animal facilities in Bangalore. 34 rats were trapped alive in and around the laboratory animal facilities in Bangalore. Urine and serum samples from theses field rats were collected. Serum samples were tested for anti-leptospiral antibodies by microscopic agglutination test, while urine samples were subjected for dark field microscopy and polymerase chain reaction to detect the presence of leptospiral antigens. Serology revealed the presence of antileptospiral antibodies in 19 (61.29 percent) field rats and dark field microscopy revealed the presence of leptospiral antigens in 3 (8.82 percent) and 6 (17.65 percent) of urine samples of these field rats. Among the serovars, Icterohaemorrhagiae was predominant followed by Autumnalis and Pyrogens. Serology dark field microscopy and polymerase chain reaction reveals that field rats are major natural carriers and shedders of leptospires.

Key words: Leptospirs, Zoonosis, Laboratory Animal, Rodent, Antibody, Antigen, Urine, Dark field microscopy,
\end{abstract} PCR.

\section{Introduction}

Leptospirosis is wide spread zoonosis caused by pathogenic spirochetes of the genus Leptospira. It assumes zoonotic importance since rodents and certain species of domestic animals such as dogs, pigs and cattle are known to be natural carriers of various serovars thus forming infection reservoirs in transmission of infection to other animals and man, especially professionally vulnerable group such as veterinarians, animal care takers. Certain vertebrate animal species have a commensal relationship with leptospires in which they are the natural hosts for pathogenic leptospires that live in their kidneys. Such leptospires do little or no detectable harm to these hosts but they maintain the infection and are therefore known as natural maintenance hosts. If other animals that are not natural maintenance hosts (including humans) are infected by the same pathogenic leptospires, they often become ill. In addition, if a maintenance host for a particular leptospire is infected with another serovar it may develop symptoms and signs of Leptospirosis (WHO 2003).

Rodents are carriers of leptospires throughout the world and are important reservoirs of infection for man and domestic animals (Twigg et al., 1969; Hathaway and Blackmore, 1981). There are three species of rodents that are distributed worldwide and are commonly associated with leptospiral infection: Mus musculus (house mouse), Rattus norvegicus (brown rat) and Rattus rattus (black rat). All three species belong to the order Rodentia, family Muridae, subfamily Murinae. In rodents, especially the common rat (Rattus norvegicus) and other reservoir species, the organisms persist indefinitely in the convoluted tubules of the kidney without causing apparent disease, and are shed into the urine in massive numbers (Dutta and Christopher et al., 2005). Rattus rattus wroughtoni hinton, Rattuis rattus rufesens, Bandicota indica and Bandicota bengalenses are the rodent species involved in spreading leptospirosis to human and live-stock in India (Gangadhar et al., 2005). With this in view the present study has been undertaken with the objectives to record the prevalence of leptospirosis in field rats in and around laboratory animal facilities in Bangalore.

\section{Materials and Methods}

Present study was undertaken at veterinary college Bangalore. 34 urine and 31 serum samples from field rats trapped alive in and around five different laboratory animal colonies in Bangalore were collected. Field rats were anesthetized by means 
Leptospires in field Rats in and around the laboratory animal facilities of Banglore, India

Table-1. Panel of leptospiral reference strains used for microscopic agglutination test.

\begin{tabular}{lll}
\hline S.No & Serogroup & Serovar \\
\hline 1 & Icterohaemorrhagiae & Icterohaemorrhagiae \\
2 & Autumnalis & Autumnalis \\
3 & Pomona & Pomona \\
4 & Pyrogens & Pyrogens \\
\hline
\end{tabular}

of Diethyl Ether inhalation. Blood samples for serology were collected by cardiac puncture. The abdomen was then opened and urine was collected from bladder under sterile conditions using $2 \mathrm{ml}$ syringe. Collected urine was then transferred to $5 \mathrm{ml}$ test tube filled with $2 \mathrm{ml}$ of Phosphate Buffer Saline (PBS). Cold chain was maintained while transporting these samples. The tubes containing blood samples were kept in a slanting position for 1 to 2 hours, serum was separated from the clotted blood by centrifuging at $2000 \mathrm{rpm}$ for $2 \mathrm{~min}$ and transferred to $2 \mathrm{ml} \mathrm{screw-}$ capped plastic vials and were stored at $-20^{\circ} \mathrm{C}$ until tested.

Microscopic agglutination test: A panel of four serovars was used for the MAT (Table 1). MAT was conducted as per the OIE (2004) in 96 well U bottom titration plates with initial dilution of $1: 100$ upto 1:1280. the highest dilution of serum showing 50 per cent reduction in number of free leptospires was considered as the end-titer.

Dark field microscopy: Urine samples collected in phosphate buffer saline were entrifuged at $12000 \mathrm{rpm}$ and the sediment suspended in small volume of PBS to form wet mount preparation and was examined under dark field microscope.

Polymerase chain reaction: PCR assay was carried out as per the method described by Gravekap et al., (1993) with slight modifications. The urine samples collected in phosphate buffer saline were centrifuged at $10,000 \mathrm{rpm}$ for 30 minutes. The pellets were resuspended in $0.1 \mathrm{ml}$ distilled water and washed two more times with distilled water. The final pellets were resuspended in $20 \mu \mathrm{l}$ of distilled water. The pellet samples were denatured at $96^{\circ} \mathrm{C}$ for 10 minutes and snap cooled in icebox. This was used as a DNA template. Amplification of DNA was performed in a total volume of $25 \mu \mathrm{l}$. The reaction mixture contained $12.5 \mu \mathrm{l}$ of master mix, $9.5 \mu \mathrm{l}$ of distilled water, $1 \mu \mathrm{l}$ of each primer G1 and G2 (Primer G1: 5'- CTG AAT CGC TGT ATAAAA GT-3', Primer G 2:5'- GGAAAA CAA ATG CTC GGA AG-3') and $2 \mu$ of DNA template. The samples were placed in automatic PCR processor (M J Research minicycler). One amplification cycle consisted of annealing of primers for 1 min at $55^{\circ} \mathrm{C}$, elongation for $2 \mathrm{~min}$ at $72^{\circ} \mathrm{C}$, and denaturation for $5 \mathrm{~min}$ at $94^{\circ} \mathrm{C}$. The number of cycles 33 were used. The last elongation step was extended to $6 \mathrm{~min}$. After amplification a $10 \mu \mathrm{l}$ portion of each sample was subjected to electrophoresis on a $1.3 \%$ agarose gel at $100 \mathrm{~V}$ for 20 to 30 minutes until the tracking dye migrated more than two third of the length of the gel tray in the buffer and the results were documented in a gel documentation system (Biorad).

\section{Results}

Seroprevalence of leptospiral antibodies by MAT among field rodents trapped from within and/or around the premises of different laboratory animal facilities revealed 19 (61.29 per cent) samples were positive by agglutinating with one or more of the four leptospira antigens tested, out of 31 sera tested. The serovar distribution among laboratory rats in the descending order was Icterohaemorrhagiae (11; 57.89 per cent), Autumnalis ( $5 ; 26.32$ per cent), Pyrogens ( 3 ; 15.78 per cent). The positive titres in field rats were $1: 100$ (5.26 per cent), 1:200 (5.26 per cent), 1:400 (15.79 per cent), 1:800 (5.26 per cent), 1:1600 (31.58 per cent), 1:3200 (26.32 per cent), 1:6400 (5.26 per cent) and 1:12800 (5.26 per cent).

Dark Field Microscopy (DFM) detected leptospires in 3 (8.82 per cent) field rat urine samples of the total 34 samples. Where as PCR detected leptospiral DNA in 6 (17.65 per cent) field rat urine samples of the total 31 samples.

\section{Discussion}

The overall seopositivity of field rats in this study was 61.29 per cent. Earlier reports from India have shown seopositivity at different levels of 88 per cent (Saadi, 1976), 7·1 per cent (Sharma et al., 2003), 58 per cent (Priya et al., 2008). The magnitude of the seropositivity alters from region to region largely attributed to climatic and environmental conditions (WHO 2003). Serovar Icterohaemorrhagiae was predominant in these field rats. But in earlier reports the predominant serovar was autumnalis in and around Madurai (Priya et al., 2008) and also in and around Bangalore (Syed, 1978). 57.9 per cent were having titre of 1600 to 3200 , where as above 3200 was 10.52 and lower than 1600 was 31.57. Titre above 800 
recorded was predominantly against Serovar Icterohaemorrhagiae.

Of the 34 urine samples of field rats, only $3(8.82$ per cent) leptospires could be detected through DFM. Only 6 (17.65 per cent) samples out of 34 urine samples were found positive for the presence of leptospiral antigen by PCR. Less positivity of PCR and DFM may be due to the less concentration of leptospiral organisms in the given samples, as minimum of $10^{4}$ leptospires $/ \mathrm{ml}$ of urine is required for detection (Paula et al., 2004). It is believed that once a rodent is infected with Leptospires it acts as carrier and irregular shedding of leptospires for the rest of its life, perpetuating the dessimination of leptospires. All the rodents showing seropositivity by MAT may not be shedding the organisms on the day the samples were collected.

\section{Acknowledgements}

The authors would like to thank The Head, Department of Livestock Production and Management, Veterinary College Bangalore, KVAFS University for providing facilities.

\section{References}

1. Dutta, T. K., Christopher, M., (2005). LeptospirosisAn overview. JAPI, 53:545-551.

2. Gangadhar, N.L., Rajasekhar, m. And Prabhudas, K., (2005). Isolation of Leptonema from rodents and cattle in India. Ind.J.Anim.Scs. 75(5): 508-510.

3. Gravekap, C., H.Van de Kemp, M.Franzen, D.Carrington, G.J.Schoon, G.J.J.M.Van Eys, C.O.R.Eerad, R.A.Hartskeerl and W.J.Terpstra, (1993). Detection of seven species of leptospires by PCR using two sets of primers. J. Gen. microbiol., 139: 1691-1700.

4. Hathaway, S., Blackmore, D., (1981). Ecological aspects of the epidemiology of infection with leptospires of the Ballum serogroup in the black rat (Rattus rattus) and the brown rat (Rattus norvegicus) in New Zealand. J. Hyg. Camb. 87: 427-436.

5. Khosho, F. K., Kaufmann, R.C., Amankwah, K.S., (1985). A simple and efficient method for obtaining urine samples from rats. Laboratory Animal Science., 35, 513-14.

6. Paula, W. A., Lucchesi, Guillermo, H., Arroyo, Analia, I. Etcheverria, Alberto, e. Parma and Alferdo, C. Seijo., (2004) Recomondation for the detection of Leptospira in urine by PCR. Revista da Sociedade Brasileira de Medicina Tropical, 37: 131-134.

7. Priya, C.G., Hoogendijk, K.T., Berg, M.V.D., Rathinam, S.R. Ahmed, A., Muthukkaruppan, V.R., Hartskeerl, R.A., (2008). Field rats form major infection source of Leptospirosis in and around Madurai, India. J. Postgrad Med.,53: 236-240.

8. Saadi, A.M. and Post, G., (1976). rodent leptospirosis in Colorado. J. Wildl. Dis., 12(3): 315-317.

9. Sharma, S., Vijayachari, P., Sugunan, A. P. and Sehgal, S.C., (2003). Epidemiology and Infection, 131: 985-989.

10. Syed N.A., (1978). Screening of rats for leptospirosis using microscopic agglutination tet and flouoresent antibody techinique. Thesis submitted to University of agriculture sciences Bangalore.

11. Twigg, G.I., Cuerden, C.M. and Hughu, d.m., (1969). Leptospirosis in British wild animals. Symp. Zool. Soc. London. 24: 75-98. (Cited in Vet.Rec., 26: 424-426).

12. Yaguer, R.H., Gochernour,W.S., Alexander, A.D., Wetmore, P.W., (1953). Natural occurrence of Leptospira ballum in rural house mice and in an possum. Proc. Soc. Exp. Biol. Med. 84: 89-590.

13. World Health Organization, (2003). Human leptospirosis: Guidance for Diagnosis, Surveillance and control. World Health Organization, Malta. 122. 